Department of Physics, Chemistry and Biology

Master Thesis

Olfactory discrimination ability of South

African fur seals (Arctocephalus pusillus)

for enantiomers

\title{
Sunghee Kim
}

LiTH-IFM- Ex--12/2627--SE

Supervisor: Matthias Laska, Linköping University

Examiner: Mats Amundin, Linköping University

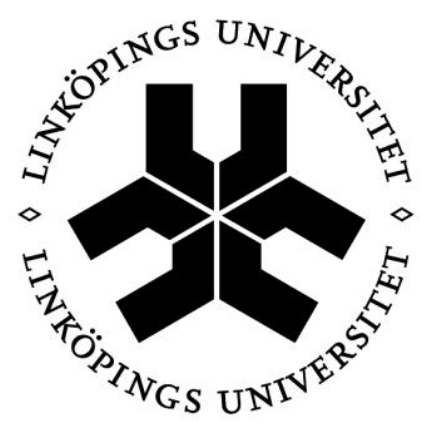

\section{Linköpings universitet}

Department of Physics, Chemistry and Biology

Linköpings universitet

SE-581 83 Linköping, Sweden 


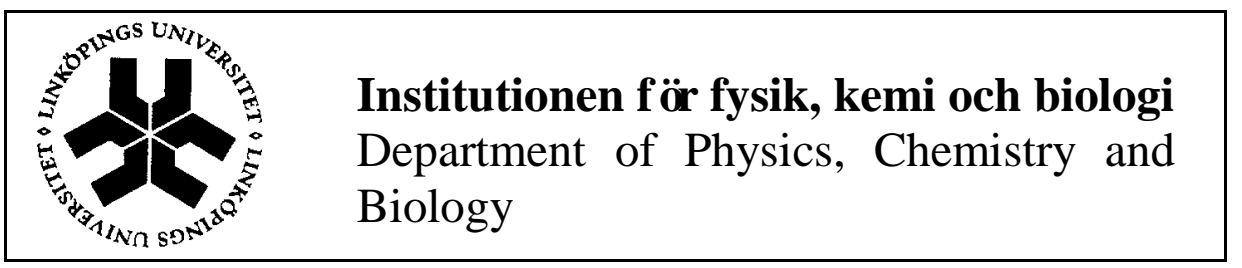

Datum/Date

2012-06-10

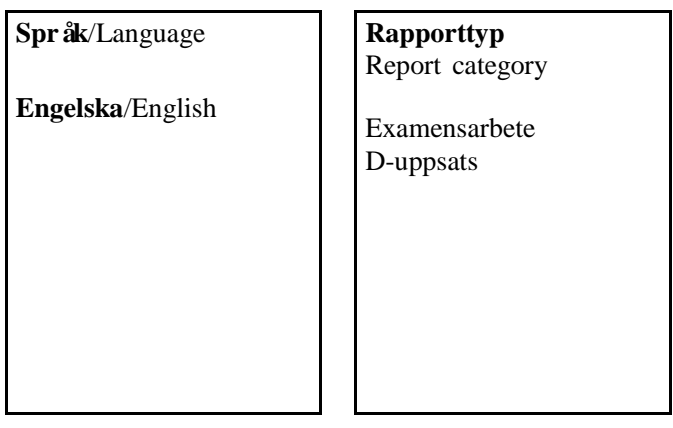

URL för elektronisk version

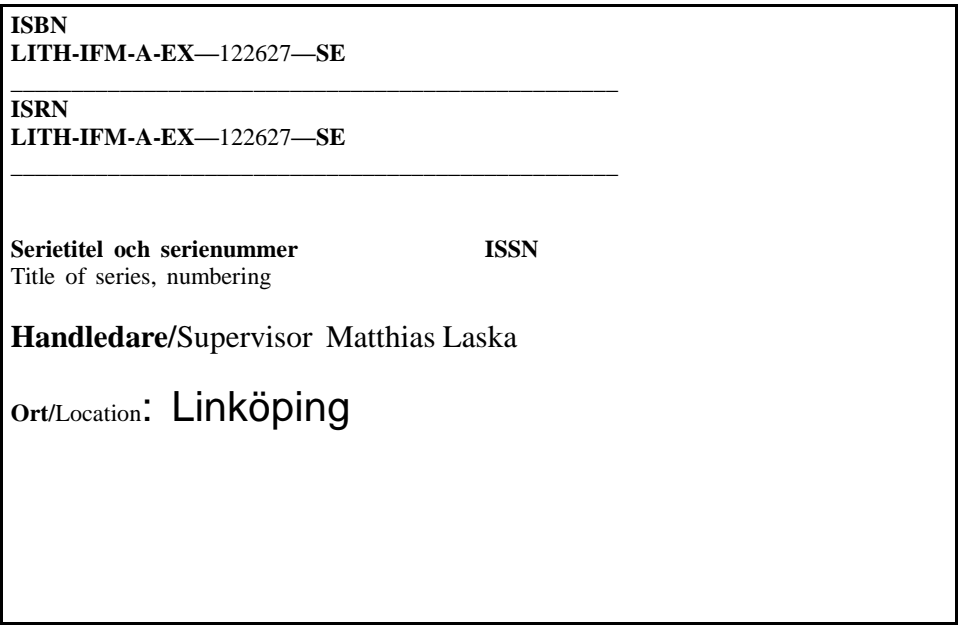

\section{Titel/Title: \\ Olfactory discrimination ability of South African fur seals (Arctocephalus pusillus) for enantiomers \\ Författare/Author: \\ Sunghee Kim}

Sammanfattning/Abstract:

The sense of smell in marine mammals is traditionally thought to be poor. However, increasing evidence suggests that pinnipeds may use their sense of smell in a variety of behavioral contexts including communication, foraging, food selection, and reproduction. Using a food-rewarded two-choice instrumental conditioning paradigm, I assessed the ability of South African fur seals, Arctocephalus pusillus, to discriminate between 12 enantiomeric odor pairs, that is, between odorants that are identical in structure except for chirality. The fur seals significantly discriminated between eight out of the twelve odor pairs (according to $p<0.05$, with carvone, dihydrocarvone, dihydrocarveol, limonene oxide, menthol, beta-citronellol, fenchone, and alphapinene), and failed with only four odor pairs (isopulegol, rose oxide, limonene, and camphor). No significant differences in performance were found between the animals ( $p>0.05)$. Cross-species comparisons between the olfactory performance of the fur seals and that of other species previously tested on the same set of odor pairs lend further support to the notion that the relative size of the olfactory bulbs is not a reliable predictor of olfactory discrimination abilities. The results of the present study suggest that sense of smell may play an important and hitherto underestimated role in regulating the behavior of fur seals.

Nyckelord/Keyword:

Arctocephalus pusillus, enantiomers, marine mammal, olfactory discrimination, pinniped, South African fur seals. 
Contents

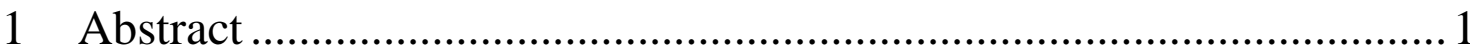

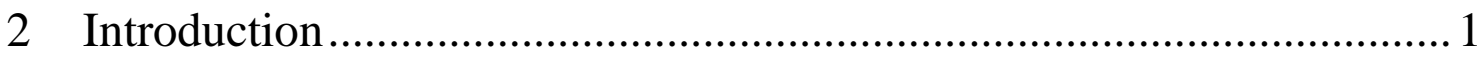

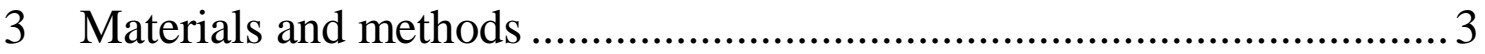

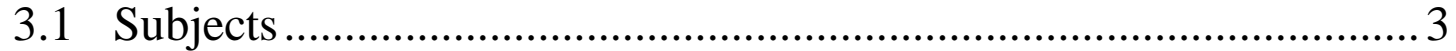

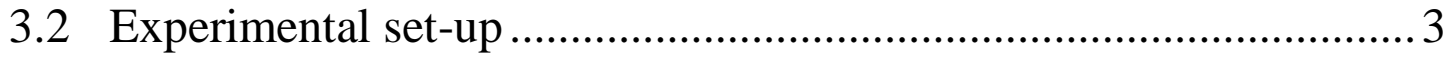

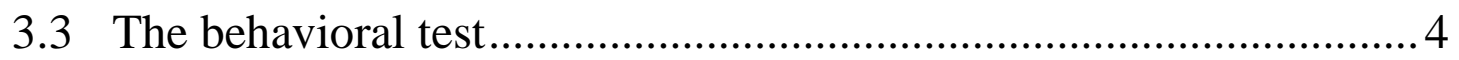

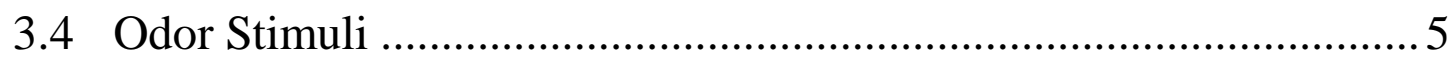

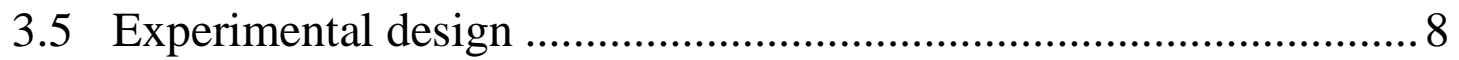

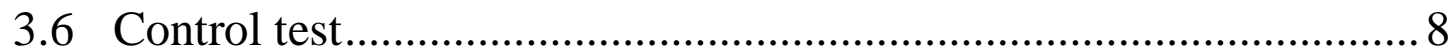

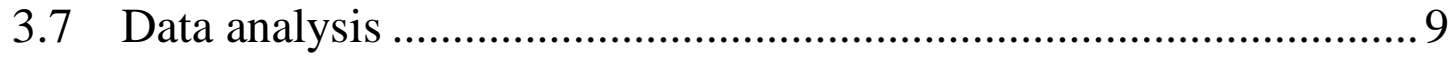

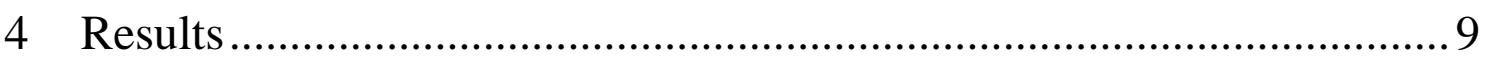

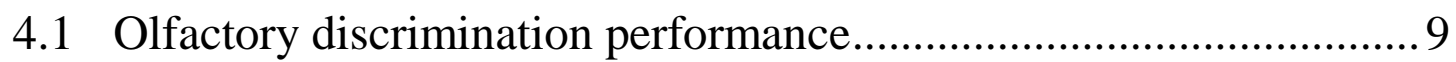

4.2 Inter-individual comparisons ...................................................... 11

4.3 Between-odorant comparisons..................................................... 13

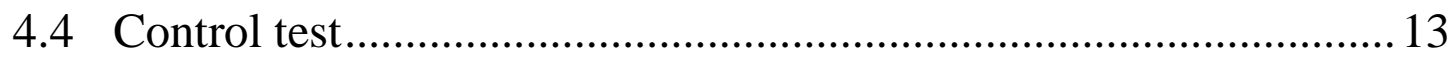

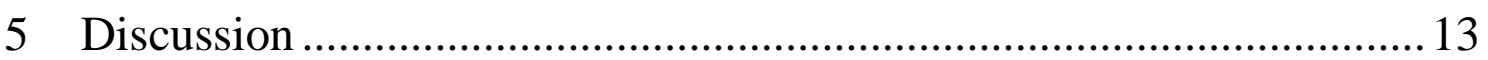

5.1 Olfactory discrimination ability of fur seals .................................... 13

5.2 Cross-species comparison.......................................................... 14

5.3 Relationship between discrimination performance and molecu-lar

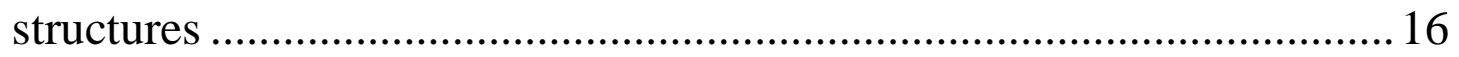

5.4 Enantiomers in the chemical environment of the fur seals.............. 17

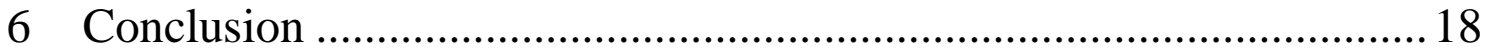

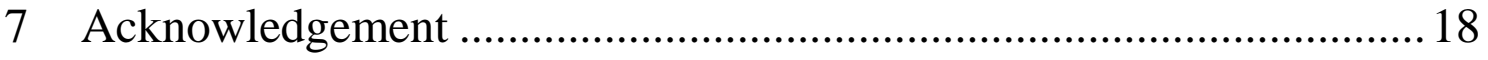

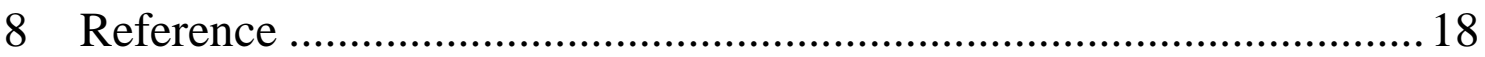




\section{Abstract}

The sense of smell in marine mammals is traditionally thought to be poor. However, increasing evidence suggests that pinnipeds may use their sense of smell in a variety of behavioral contexts including communication, foraging, food selection, and reproduction. Using a food-rewarded twochoice instrumental conditioning paradigm, I assessed the ability of South African fur seals, Arctocephalus pusillus, to discriminate between 12 enantiomeric odor pairs, that is, between odorants that are identical in structure except for chirality. The fur seals significantly discriminated between eight out of the twelve odor pairs (according to $p<0.05$, with carvone, dihydrocarvone, dihydrocarveol, limonene oxide, menthol, betacitronellol, fenchone, and alpha-pinene), and failed with only four odor pairs (isopulegol, rose oxide, limonene, and camphor). No significant differences in performance were found between the animals $(\mathrm{p}>0.05)$. Cross-species comparisons between the olfactory performance of the fur seals and that of other species previously tested on the same set of odor pairs lend further support to the notion that the relative size of the olfactory bulbs is not a reliable predictor of olfactory discrimination abilities. The results of the present study suggest that sense of smell may play an important and hitherto underestimated role in regulating the behavior of fur seals.

Key words: Arctocephalus pusillus, enantiomers, marine mammal, olfactory discrimination, pinniped, South African fur seals.

\section{Introduction}

Marine mammals are traditionally considered to have a poorly developed sense of smell. Pinnipedia, the mammalian sub-order comprising aquatic carnivores such as fur seals and sea lions, are therefore believed to be microsmatic (having a poor sense of smell). This belief is mainly based on an interpretation of neuroanatomical and genetic evidence, such as a reduced size of the olfactory bulbs and a low number of functional olfactory genes (Fobes \& Smock 1981, Reep et al. 2007). However, the fact that both peripheral and central olfactory structures exist in pinnipeds challenges this assumption of poor olfactory capacity (Kuzin \& Sobolevsky 1976, cited by Lowell \& Flanigan 1980, Watkins \& Wartzock 1985). Furthermore, an increasing number of behavioral studies suggest that pinnipeds may use their sense of smell in a variety of behavioral contexts including social communication, foraging, food selection, and reproduction. 
A number of studies have reported that, in the wild, mother seals recognize their pups via olfactory investigation. Trimble \& Inseley (2010) found that olfactory investigation was conducted by South American sea lion mothers, Otaria flavescens, during $97.6 \%$ of total mother-pup reunions they observed. Harp seals, Phoca groenlandica, also identify their own pups through olfactory cues (Kovacs 1995). Pitcher et al. (2011) tested filial pup recognition in wild Australian sea lions, Neophoca cinerea. They used two identical stuffed model pups with filial and non-filial pup's odorants on each model. Mothers sniffed the model with its filial pup's odor significantly more than the model with a non-filial pup's odor. The authors concluded that Australian sea lion females can differentiate between the odor of their own pup and that of another pup.

Olfactory investigation is also conducted between male and female seals. Frequent nuzzling behavior by males at females' facial and perineal regions during the breeding season has been observed in South African fur seals, Arctocephalus pusillus (Ross 1972), and New Zealand fur seals, Arctocephalus forsteri (Miller 1974). Also, male ringed seals, Phoca hispida, and grey seals, Halichoerus grypus, have been described to emit strong odors during the rut. These secretions are thought to be used for territorial marking, protection from predator attacks and/or attracting females (Hardy \& Roff 1991, Ryg et al. 1992).

Using a go/no-go response paradigm, Kowalevsky et al. (2006) showed that Harbour seals, Phoca vitulina vitulina, possess a high sensitivity for the odor of dimethyl sulphide, which is a reliable indicator for profitable foraging areas. Laska et al. $(2008,2010)$ demonstrated that South African fur seals can be trained to respond to odor stimuli, and that they possess well-developed olfactory learning and discrimination capabilities, and an excellent long-term memory for odors.

In the present study I continued to explore the sense of smell in South African fur seals and assessed their ability to discriminate between the odors of 12 pairs of enantiomers. Enantiomers are particularly useful for assessing olfactory discrimination abilities because the (+)-form and the (-)-form of a given enantiomer are identical in most of their physical properties such as size, shape, and electrical charge distribution but only differ from each other in chirality, that is, enantiomers are nonsuperposable mirror images of each other. 


\section{Materials and methods}

\subsection{Subjects}

Testing was carried out using four adult female (Flisa, Tinny, Sealia, and Villma) South African fur seals, Arctocephalus pusillus, maintained as part of a group of seven animals at Kolmården Wild Animal Park, Sweden. The group was housed under seminatural conditions in an $800 \mathrm{~m}^{2}$ outdoor pool with an adjacent house bearing eight cages which allowed temporary separation of animals for individual testing. All animals were trained to enter the individual cages voluntarily and were completely accustomed to the procedure. Animals were fed with fish (mackerel, Scomber scombrus; capelin, Mallotus villosus; herring, Clupea harengus) and squid (Argentine shortfin squid, Ommastrephes argentinus) three times a day. No food deprivation schedule was adopted. Rather, the food reward given to the animals during the sessions of this project was part of their three feeding bouts per day. The experiments reported here comply with the Guide for the Care and Use of Laboratory Animals (National Institutes of Health Publication no. 86-23, revised 1985) and also with current Swedish laws.

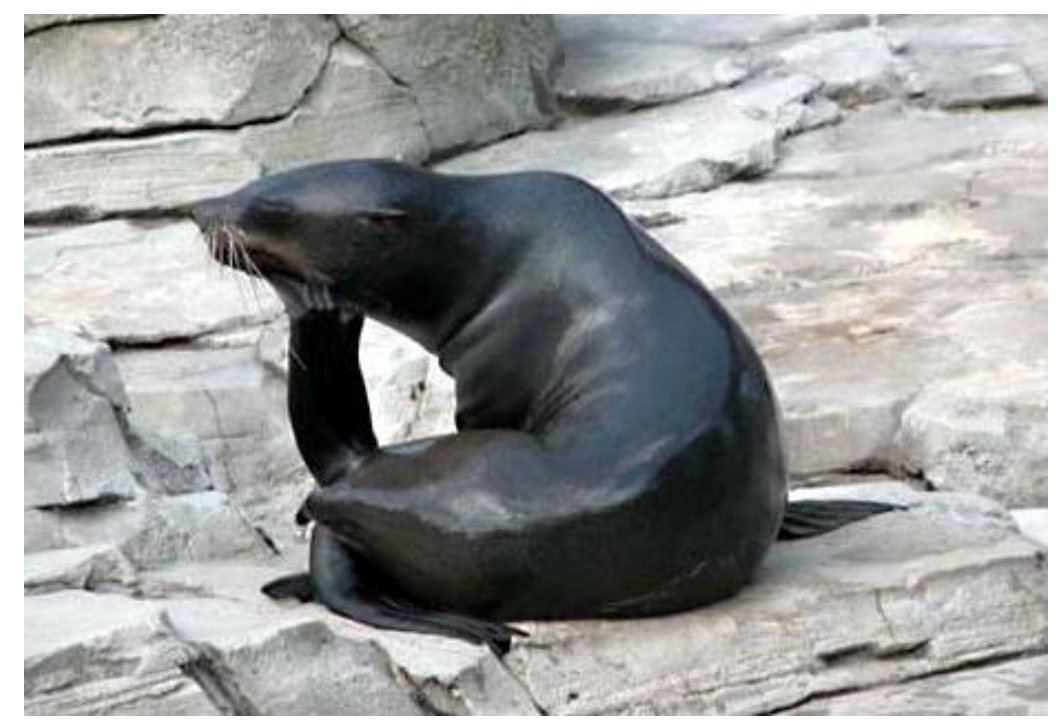

Figure 1. A South African fur seal (Arctocephalus pusillus)

\subsection{Experimental set-up}

The behavioral test was based on a food-rewarded, two-choice, instrumenttal conditioning paradigm. In a previous study (Laska et al. 2008) the animals had learned to sniff at two odor sampling ports and then to indicate which of the two options held the rewarded stimulus by poking their nose into the corresponding sampling port. An opaque PVC board $50 \mathrm{~cm}$ high 
$\times 100 \mathrm{~cm}$ wide $\times 1 \mathrm{~cm}$ thick) with two openings $(7.5 \mathrm{~cm}$ diameter $)$ at equal height and $42 \mathrm{~cm}$ apart from each other was mounted at the front side of the test cage in such a way that the openings were $47 \mathrm{~cm}$ above the ground. For the presentation of the odor stimuli two high density polyethylene (HDPE) containers with tight-fitting removable lids (Rubbermaid Cooling Bags, $35 \mathrm{~cm}$ high $\times 35 \mathrm{~cm}$ wide $\times 20 \mathrm{~cm}$ deep) were used. Each lid was equipped with a battery-powered ventilator $(6 \mathrm{~cm}$ diameter) providing an ingoing airflow. A total of 130 holes of $3 \mathrm{~mm}$ diameter placed in intervals of even distance forming a filled circle with a diameter of 7.5 $\mathrm{cm}$ were drilled in an exact pattern in the middle of one of the front sides of each container serving as an outlet for the airflow provided by the ventilator. The outgoing airflow was adjusted to $8 \mathrm{~L}$ per minute and a platform on the outside of the cage ensured that the containers could be placed with their outlets congruent with the openings of the PVC board. In order to present the odor stimuli, $1 \mathrm{ml}$ of an odorant was pipetted onto the filter paper in a Petri dish which, in turn, was placed into an opaque HDPE box $(12 \mathrm{~cm}$ high $\times 20 \mathrm{~cm}$ wide $\times 12 \mathrm{~cm}$ deep $)$ without a lid inside the containers. This allowed the airflow provided by the ventilator to reach the surface of the odor stimuli and, at the same time, prevented the animals from using visual cues. A mirror placed on top of the cage allowed the experimenter to observe the animal's behavior without being seen behind the opaque polyvinyl chloride board (see Figure 2). It was shown that the mirror didn't affect the animal's behavior in a previous study using the same method (Laska et al. 2008).

\subsection{The behavioral test}

At the beginning of each trial, the two containers were placed with their outlets toward the odor sampling ports and the animal was allowed to sniff at them as often as it liked. Immediately following the animal's decision (a nose pokes into one of the two odor sampling ports), the two containers were removed and, in the case of a correct response (a nose poke into the odor sampling port presenting the rewarded stimulus), the animal was rewarded with fish or squid. In the case of an incorrect response (a nose poke into the odor sampling port presenting the unrewarded stimulus) no reward was given to the animal. Twenty such trials were performed per session and usually two sessions were performed per animal and day. Care was taken to present the rewarded stimulus to the right or the left odor sampling port adopting a pseudo-randomized sequence with the limitation that the same option was not used more than three times in a row. At the end of each session, the containers and the boxes bearing the odor stimuli were 
thoroughly cleaned using perfume-free detergent and rinsed with dematerialized water.

A previous study in which the same experimental set-up was used (Laska et al. 2008) and which included double-blind trials as well as control trials using different containers gave no indication that the animals might use unintended cues from the experimenter or from the equipment.
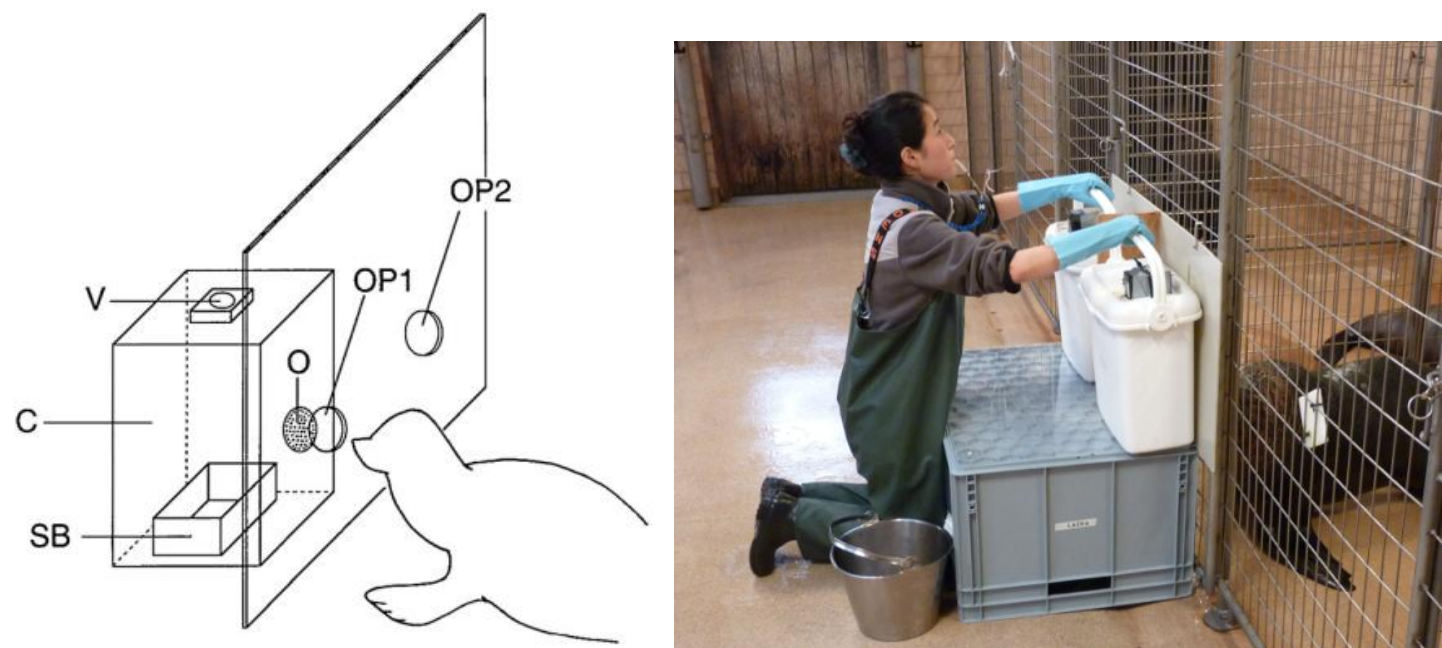

Figure 1. Left: Schematic drawing of the experimental set-up used to assess olfactory performance in South African fur seals. C: container, V: ventilator for ingoing airflow, SB: Stimulus box, O: outlet for outgoing airflow, OP1: odor port 1, OP2: odor port 2. The second, identically built container placed behind odor port 2, is not shown. Right: Photo of the experimental set-up. The behavior of the animal was observed using a mirror attached to the top of the fence (not shown in this photo) in order to avoid any inadvertent interaction between experimenter and the animal during the session.

\subsection{Odor Stimuli}

A set of 12 enantiomeric odor pairs was used (see Table 1 and Figure 3). All substances were obtained from Sigma-Aldrich (St. Louis, MO, USA) and Fluka (Seelze, Germany) and had a nominal purity of at least $99 \%$. They were diluted using NEAR-odorless diethyl phthalate (Sigma-Aldrich) as the solvent. The level of dilution was chosen to provide stimuli that were easily detectable and of approximately equal subjective intensity for humans when smelled at the outlet of the stimulus containers. The rationale for choosing these substances was to use odorant pairs that are identical in their chemical and physical properties except for chirality. Furthermore, data on discrimination performance for the same set (or sub-sets) of stimuli from other species (CD-1 mice: Laska \& Shepherd 2007; human subjects: Laska \& Teubner 1999, Laska 2004; squirrel monkeys and pigtail macaques: Laska et al. 1999, Laska et al. 2005; honeybees: Laska \& Galizia 
2001; SD/LE rats: Linster et al. 2001, Rubin \& Katz 2001; Asian elephants: Rizvanovic 2012) are at hand allowing cross-species comparisons of discrimination performance. Additionally, the essential oil of black pepper oil (Piper nigrum) was used. This odorant had been used in a previous study as unrewarded stimulus (Laska et al. 2008) and was thus familiar to the animals.

Table 1. Information about the substances used

\begin{tabular}{|c|c|c|c|}
\hline Enantiomer & CAS \# & Chemical description & Dilution \\
\hline$(\mathrm{S})$-(+)-carvone & $2244-16-8$ & Monocyclic terpene-keton & $1: 3$ \\
\hline (R)-(-)-carvone & $6485-40-1$ & Monocyclic terpene-keton & $1: 3$ \\
\hline (+)-dihydrocarvone & $5524-05-0$ & Monocyclic terpene-keton & $1: 2$ \\
\hline (-)-dihydrocarvone & $7764-50-3$ & Monocyclic terpene-keton & $1: 2$ \\
\hline (+)-dihydrocarveol & $22567-21-1$ & Monocyclic terpene-alcohol & $1: 2$ \\
\hline (-)-dihydrocarveol & $20549-47-7$ & Monocyclic terpene-alcohol & $1: 2$ \\
\hline (R)-(+)-limonene & $5989-27-5$ & Monocyclic terpene-hydrocarbon & $1: 3$ \\
\hline (S)-( -)-limonene & $5989-54-8$ & Monocyclic terpene-hydrocarbon & $1: 3$ \\
\hline (+)-limonene oxide & $2485-30-59$ & Monocyclic terpene-epoxide & $1: 3$ \\
\hline (-)-limonene oxide & $2485-06-0$ & Monocyclic terpene-epoxide & $1: 3$ \\
\hline (+)-isopulegol & $104870-56-6$ & Monocyclic terpene-alcohol & $1: 5$ \\
\hline$(-)$-isopulegol & $89-79-2$ & Monocyclic terpene-alcohol & $1: 5$ \\
\hline$(1 \mathrm{~S}, 2 \mathrm{R}, 5 \mathrm{~S})-(+)-$ menthol & $15356-60-2$ & Monocyclic terpene-alcohol & $1: 10$ \\
\hline$(1 \mathrm{R}, 2 \mathrm{~S}, 5 \mathrm{R})-(-)$-menthol & $2216-51-5$ & Monocyclic terpene-alcohol & $1: 10$ \\
\hline$(R)-(+)-\beta$-citronellol & $1117-61-9$ & Acyclic terpene-alcohol & $1: 3$ \\
\hline$(S)-(-)-\beta$-citronellol & $7540-51-4$ & Acyclic terpene-alcohol & $1: 3$ \\
\hline (+)-rose oxide & $16409-43-1$ & Monocyclic terpene-oxide & $1: 3$ \\
\hline$(-)$-rose oxide & $5258-11-7$ & Monocyclic terpene-oxide & $1: 3$ \\
\hline (+)-fenchone & $4695-62-9$ & Bicyclic terpene-keton & $1: 3$ \\
\hline (-)-fenchone & $7787-20-4$ & Bicyclic terpene-keton & $1: 3$ \\
\hline (+)-a-pinene & $7785-70-8$ & Bicyclic terpene-hydrocarbon & $1: 5$ \\
\hline (-)-a-pinene & $7785-26-4$ & Bicyclic terpene-hydrocarbon & $1: 5$ \\
\hline (1R)-(+)-camphor & $464-49-3$ & Bicyclic terpene-keton & $1: 10$ \\
\hline (1S)-( -)-camphor & $464-48-2$ & Bicyclic terpene-keton & $1: 10$ \\
\hline
\end{tabular}




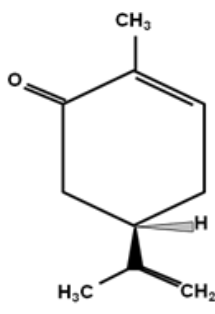

(-)-carvone

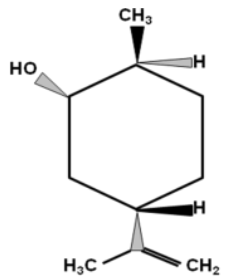

(-)-dihydrocarveol

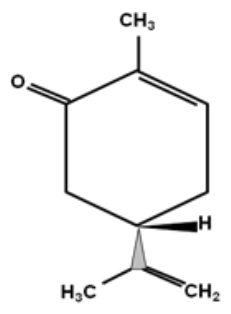

(+)-carvone

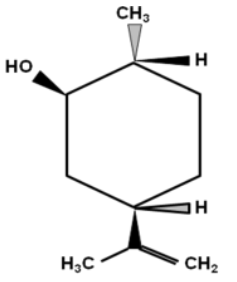

(+)-dihydrocarveol

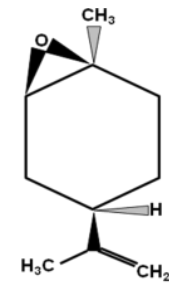

(-)-limonene oxide

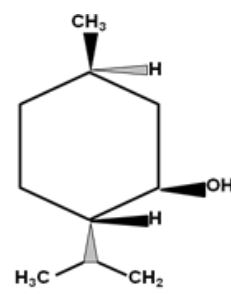

(-)-menthol

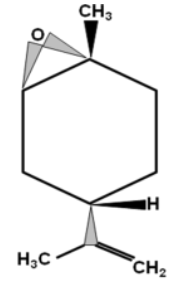

(+)-limonene oxide

(+)-menthol

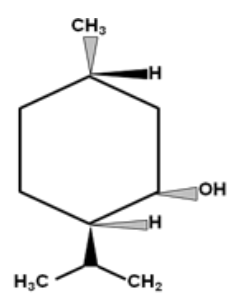<smiles>CC(C)CC1CC(C)(C)CCO1</smiles>

(-)-rose oxide

(-)-rose oxide

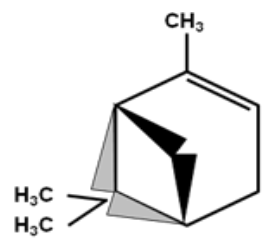

(-)-u-pinene

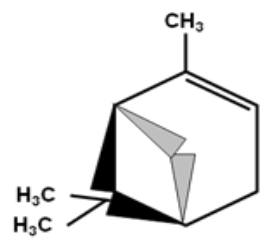

(+)- $\alpha$-pinene
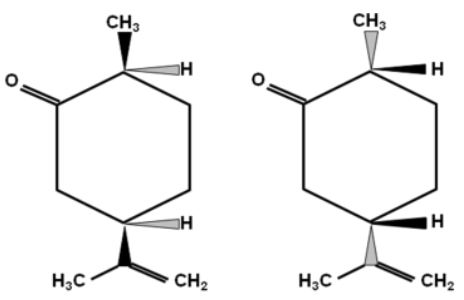

(-)-dihydrocarvone

(+)-dihydrocarvone
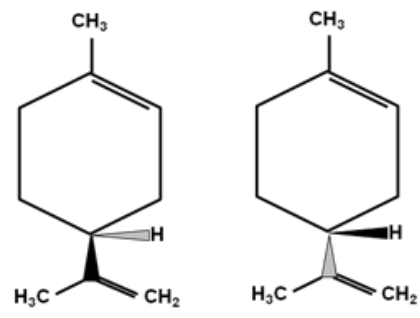

(-)-limonene

(+)-limonene<smiles>CC(C)[C@@H]1CC[C@@H](C)C[C@H]1O</smiles>

$(-)$-isopulegol<smiles>CC(C)=CCC[C@H](C)CO</smiles><smiles>CC(C)=CCC[C@@H](C)CO</smiles>

(-)- $\beta$-citronellol

(+)- $\beta$-citronellol
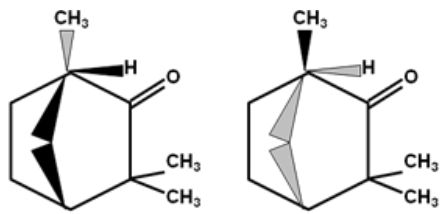

(-)-fenchone

(+)-fenchone

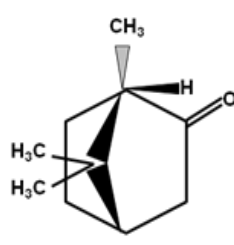

(-)-camphor

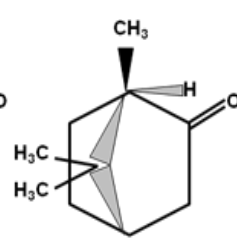

(-)-camphor

Figure 3. Molecular structures of the 12 pairs of enantiomers used. 


\subsection{Experimental design}

Two of the four animals were trained to associate the (+)-form of a given enantiomeric odor pair as the rewarded stimulus, and the other two animals were trained to associate the (-)-form of the same enantiomeric odor pair as the rewarded stimulus. To allow an animal to build a robust association between a given odorant and its significance as rewarded stimulus, each fur seal received 5 to 10 sessions of 20 trials, using pepper oil as unrewarded stimulus. Once familiarized with the rewarded stimulus, the black pepper oil was exchanged for the other form of the same enantiomer and this enantiomeric odor pair was presented for 4 sessions. The same procedure of 5 to 10 training sessions (either form of enantiomers versus black pepper) and 4 critical sessions (the (+) form of enantiomer versus the (-)-form of enantiomer) was conducted with all enantiomeric odor pairs used in this study. If needed, up to two sessions with black pepper oil as unrewarded stimulus were implemented between the different test combinations in order to boost the animal's confidence and to refresh its memory for the reward value of the rewarded stimulus.

With the enantiomers of limonene, only three of the four animals could be tested as one animal (Sealia) was injured on her right flipper, which did not allow her to lift up her upper body to participate in the test. Furthermore, with four pairs of enantiomers (limonene oxide, isopulegol, menthol and alpha-pinene), only three animals (Tinny, Sealia and Villma) were tested as Flisa had to be euthanized due to health problems.

\subsection{Control test}

In order to exclude the possibility that the animals used unintended cues, control tests were conducted during four critical sessions with the enantiomers of fenchone.

The controls were performed based on suspicions about the following possible cues: the ventilators attached to the lids might slightly differ in their sound, tiny differences in the pattern of holes on the containers, and residual smell from previous odorants on the lids or on the containers might give hints. During the first two sessions, the same containers that the animals had encountered during previous tasks were presented, but the lids were switched in order to test for the possibility of cues from the lid. During the next two sessions the containers were switched, but the same 
lids that the animals had encountered during previous tasks were used in order to test for the possibility of cues from the container.

\subsection{Data analysis}

In the method described here, the animal has two options: (1) to correctly respond to the positive stimulus (hit), and (2) to falsely respond to the negative stimulus (false alarm). The percentage of correct decisions was used as the measure of performance.

In all tasks, two levels of criterion performance were used: a more liberal criterion was set at $67.5 \%$ correct choices in the best two consecutive sessions (corresponding to $\mathrm{p}<0.05$, two-tailed binomial test), and a more rigorous criterion was set at $72.5 \%$ correct choices in two consecutive sessions (corresponding to $\mathrm{p}<0.01$, two-tailed binomial test).

Comparisons of performance across individuals were made using the Mann-Whitney U-test for independent samples.

The number of animals tested in the present study was too low to allow for statistical evaluation of discrimination performance at the group level. Therefore, the following criteria were adopted:

With the odor pairs that were tested with four animals, at least three of them had to reach the criterion of $p<0.05$ so that the fur seals as a group were considered as being capable of discriminating a given odor pair.

With the odor pairs that were tested with only three animals, all three had to reach the criterion of $\mathrm{p}<0.05$ so that the fur seals as a group were considered as being capable of discriminating a given odor pair.

\section{Results}

\subsection{Olfactory discrimination performance}

Figure 4 describes the performance of four South African fur seals in discriminating between twelve pairs of enantiomers. The performance scores ranged from $57.5 \%$ correct choices (Sealia, on the task with the enantiomers of carvone) to $92.5 \%$ (Flisa, on the task with the enantiomers of dihydrocarvone). 
All tested animals reached both criteria $(72.5 \%$ correct choices, $\mathrm{p}<0.01$ and $67.5 \%$ correct choices, $\mathrm{p}<0.05)$ in discriminating between the $(+)-$ form and the (-)-form of dihydrocarveol, limonene oxide, menthol, fenchone, and alpha-pinene (see Figure 4).

According to the more strict criterion of $72.5 \%$ correct choices (corresponding to $\mathrm{p}<0.01$ ), the animals as a group succeeded in discriminating between seven out of twelve enantiomeric odor pairs (carvone, dihydrocarvone, dihydrocarveol, limonene oxide, menthol, fenchone, and alphapinene). In the tasks with the enantiomers of dihydrocarveol, and fenchone all of the four animals succeeded, and all of the three animals tested succeeded the tasks with the enantiomers of limonene oxide, menthol, and alpha-pinene. Among the tasks in which all four animals were tested, only one animal failed to reach the criterion with the enantiomers of carvone and dihydrocarvone. Two out of the four animals reached the criterion with beta-citronellol. Only one out of the four animals succeeded in discriminating between the enantiomers of camphor, and one out of the three animals tested succeeded the tasks with the enantiomers of isopulegol. None of them reached the criterion in the tasks with the enantiomers of limonene and rose-oxide (see Figure 4).

According to the more liberal criterion of $67.5 \%$ correct choices (corresponding to $\mathrm{p}<0.05$ ), the group of animals succeeded in discriminating between eight out of twelve enantiomeric odor pairs (carvone, dihydrocarvone, dihydrocarveol, limonene oxide, menthol, beta-citronellol, fenchone, and alpha-pinene), and in all twelve tasks, at least one animal reached the criterion. All of the four animals succeeded the tasks with the enantiomers of dihydrocarveol, and fenchone, and all of the three animals tested succeeded in the tasks with the enantiomers of limonene oxide, menthol, and alpha-pinene. Among the tasks with the enantiomers of carvone, dihydrocarvone, and beta-citronellol only one out of the four animals failed to reach the criterion. Two out of the four animals succeeded in discriminating between the (+)-form and the (-)-form of rose oxide, and two out of the three animals succeeded the task with isopulegol. In the task with camphor only one out of the four animals reached the criterion, and in the task with limonene only one out of the three animals tested reached the criterion (see Figure 4). 


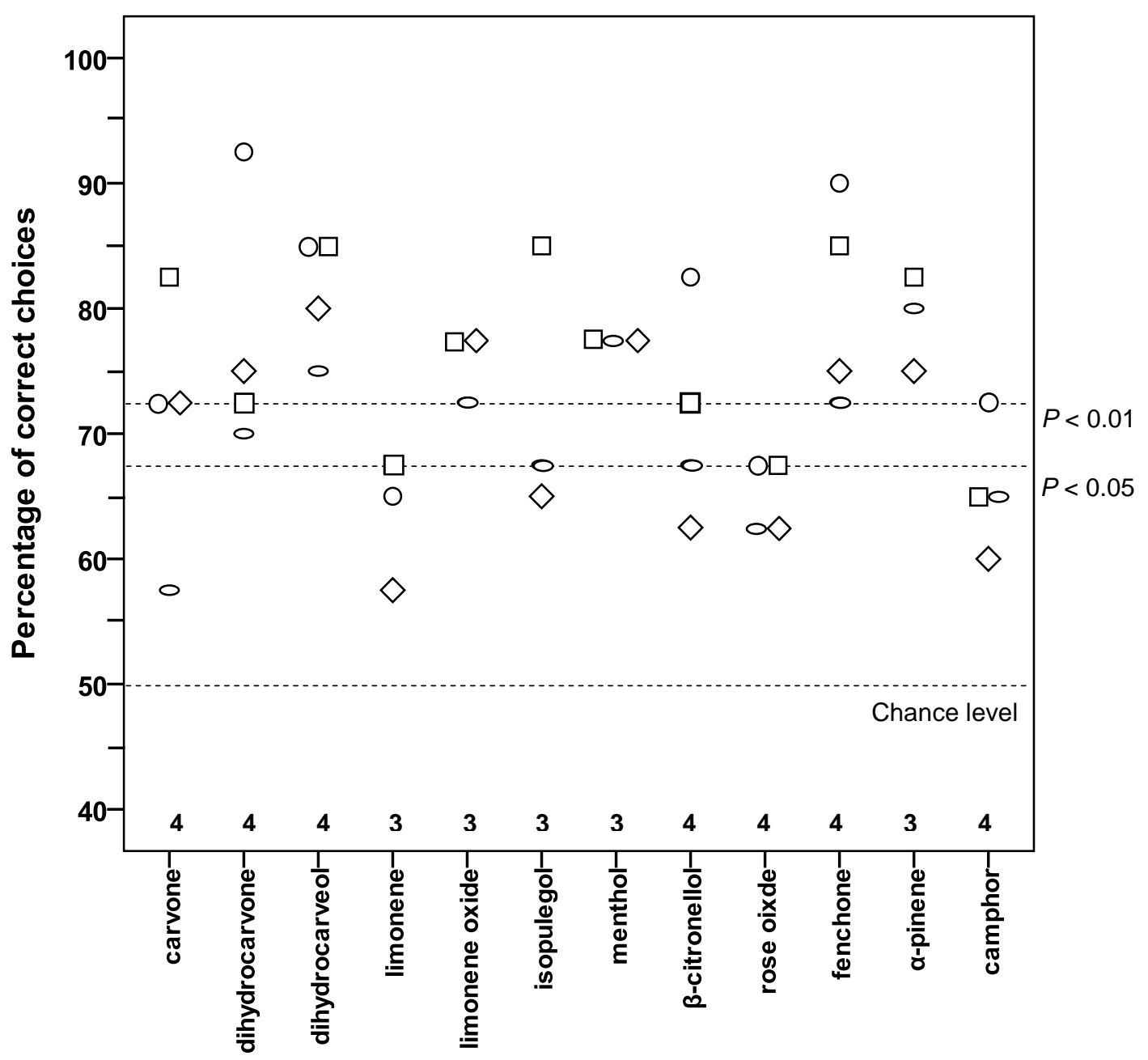

Figure 4. Performance of four South African fur seals in discriminating between twelve pairs of enantiomers. Each data point represents percentage of correct choices from 40 decisions in two consecutive sessions per animal (Flisa, circle; Tinny, square; Sealia, oval; Villma, diamond). Figures above abscissa indicate the number of animals tested on each task. The dashed horizontal lines indicate chance level (at $50 \%$ ), and criterion level (at $67.5 \%$, corresponding to $p<0.05$, and $72.5 \%$, corresponding to $p<0.01$, respectively).

\subsection{Inter-individual comparisons}

Figure 4 describes that Tinny succeeded with nine out of twelve discrimination tasks with the enantiomers of carvone, dihydrocarvone, dihydrocarveol, limonene oxide, isopulegol, menthol, beta-citronellol, fenchone, and alpha-pinene according to the more strict criterion of $72.5 \%$ correct choices ( $\mathrm{p}<0.01)$, and additionally with limonene and rose oxide according to the more liberal criterion of $67.5 \%$ correct choices $(\mathrm{p}<0.05)$. 
Villma succeeded in discriminating between the (+)-form and (-)-form of seven out of twelve enantiomeric odor pairs (carvone, dihydrocarvone, dihydrocarveol, limonene oxide, menthol, fenchone, and alpha-pinene) according to the more strict criterion of $72.5 \%$ correct choices $(\mathrm{p}<0.01)$, and failed to reach the more liberal criterion of $67.5 \%$ correct choices $(\mathrm{p}<$ 0.05 ) with the remaining five odor pairs. Sealia succeeded with five out of eleven enantiomeric odor pairs (dihydrocarveol, limonene oxide, menthol, fenchone, and alpha-pinene) according to the more strict criterion of $72.5 \%$ correct choices, and additionally with three enantiomeric odor pairs (dihydrocarveol, isopulegol, and beta-citronellol) according to the more liberal criterion of $67.5 \%$ correct choices. Flisa succeeded in discriminating between six out of eight enantiomeric odor pairs (carvone, dihydrocarvone, dihydrocarveol, beta-citronellol, fenchone, and camphor) according to the more strict criterion of $72.5 \%$ correct choices $(\mathrm{p}<0.01)$, and she additionally reached the more liberal criterion of $67.5 \%$ correct choices $(\mathrm{p}$ $<0.05)$ with rose oxide.

Among the tested animals, either Flisa or Tinny was the best performer on a majority of tasks. Tinny was the best performer in eight out of twelve tasks (carvone, dihydrocarveol, limonene, limonene oxide, isopulegol, menthol, rose oxide, and alpha-pinene) with the $85.0 \%$ correct choices as the highest score on tasks with the enantiomers of dihydrocarveol and isopulegol. Flisa scored the highest percentage of correct choices in six tasks out of eight (dihydrocarvone, dihydrocarveol, beta-citronellol, rose oxide, fenchone, and camphor), and the highest score she had was $92.5 \%$ correct choices with dihydrocarvone. Villma showed the highest score in two tasks with the enantiomeric odor pairs of limonene oxide $(77.5 \%)$ and menthol. Although Sealia scored best result in one task with the enantiomers of menthol, the other animals (Tinny, Villma) also scored the same result $(77.5 \%)$.

The highest percentage of correct choices of Flisa was $92.5 \%$ in the task with the enantiomers of dihydrocarvone. Tinny scored $85.0 \%$ correct choices with the pair of dihydrocarveol, isopulegol, and fenchone. Sealia discriminated the enantiomers of alpha-pinene best $(80.0 \%)$ among eleven enantiomeric odor pairs, whereas Villma discriminated between the $(+)-$ form and the (-)-form of dihydrocarveol best $(80.0 \%)$.

The average scores of each animal were as follows: Flisa scored an average of $78.4 \%$ from eight tasks, Tinny scored $76.7 \%$ from twelve tasks, Villma scored $70.0 \%$ from twelve tasks, and Sealia scored $69.8 \%$ from eleven 
tasks.

The interindividual variability was generally small. With only one exception (Tinny vs. Sealia, $\mathrm{p}<0.05$ ), no significant differences in performance were found between the animals (all other pairwise comparisons: $\mathrm{p}>0.05$ ). Across all tasks, the mean range between the best- and the poorest-scoring animal was only $12.9 \%$. The biggest difference in scores between animals in a given task was $25 \%$ with the enantiomers of carvone. In contrast, all of the three animals tested scored the same percentage of correct choices $(77.5 \%)$ in the task with the enantiomers of menthol.

\subsection{Between-odorant comparisons}

The average score of all animals tested in a given task was highest in the task with dihydrocarveol $(81.3 \%)$, and lowest in the task with limonene $(63.3 \%)$. The ranking of the average scores per task from the highest to the lowest was dihydrocarveol $(81.3 \%)$, fenchone $(80.6 \%)$, alpha-pinene $(79.2 \%)$, dihydrocarvone and menthol (77.5\%), limonene oxide $(75.8 \%)$, isopulegol $(72.5 \%)$, carvone and beta-citronellol $(71.3 \%)$, camphor $(65.6 \%)$, rose oxide $(65.0 \%)$, and limonene $(63.3 \%)$.

\subsection{Control test}

The scores that the animals yielded during four control sessions did not show any remarkable difference from each other. Also, a difference in the discrimination performance and behavior of each animal was not observed. Therefore, the possibility of using inadvertent cues was excluded.

\section{Discussion}

This study demonstrates that South African fur seals possess welldeveloped olfactory discrimination ability for enantiomeric odor pairs, which is not generally poorer than that of other species previously tested on the same set of odor pairs. This result is surprising given that marine mammals are considered to have a poorly developed sense of smell.

\subsection{Olfactory discrimination ability of fur seals}

The results of this study show that South African fur seals are capable of discriminating the majority of enantiomeric odor pairs tested (eight of the twelve odor pairs tested, according to $\mathrm{p}<0.05)$. This result refutes the 
notion that marine mammals are considered to have a poorly developed sense of smell. The argument of poor olfactory capacity in marine mammals is mainly based on an interpretation of anatomical and genetic studies. Reep et al. (2007) reported a reduced size of the olfactory bulbs in pinnipeds and sirenians compared with that of terrestrial mammals in relation to overall brain size; they suggested that this reduced size of the olfactory bulbs is because marine mammals do not have a way to use this sensory system in an underwater environment. However, the idea of olfactory systems not being used underwater lacks rational evidence. Water shrews, another semi-aquatic mammal, preferentially use their olfactory system to detect their prey underwater (Catania et al. 2008). Similarly, the birds' sense of smell was long thought to be poor on the basis of anatomical findings (Bang \& Cobb 1968, Welty 1975), but behavioral studies have demonstrated that several species of birds possess highly sensitive olfactory systems (Benvenuti et al. 1977, Caspers \& Tobias 2011, Amo et al. 2012 in press). Similarly, it has been found that the number of olfactory receptor genes is not a reliable predictor for an animal's olfactory capacity. Laska et al. (2005) reported comparable olfactory capacities in three primate species (humans, squirrel monkeys and pigtail macaques), which does not correspond with the different number of functional olfactory receptor genes between these species.

In conclusion, anatomical or genetic features are poor predictors of the efficiency of the olfactory system of a variety of animals, and thus probably also of those of marine mammals. An increasing number of behavioral studies suggest that the capacity of the olfactory system of pinnipeds have been underestimated. In an earlier study, Laska et al. (2010) showed that fur seals successfully discriminated between structurally related aliphatic odorants employing the same method that was used here. The result of the present study lends even stronger support to the idea of a well-developed olfactory discrimination capacity of South African fur seals, given that the enantiomers differ only in chirality and thus represent a real challenge to any olfactory system.

\subsection{Cross-species comparison}

A comparison between the olfactory discrimination performance of South African fur seals and that of other species, tested on the same set of enantiomeric odor pairs, demonstrates that the olfactory performance of the fur seals is not generally poorer than that of the other species (see Table 2). The fur seals succeeded in discriminating between a higher number of 
enantiomeric odor pairs than humans (Laska \& Teubner 1999, Laska 2004) and squirrel monkeys (Laska et al. 1999, Laska et al. 2005) that were tested with the same 12 enantiomeric odor pairs. Whereas the South African fur seals discriminated between eight odor pairs, human subjects and squirrel monkeys were only able to discriminate between five and six of the twelve pairs of optical isomers, respectively. Pigtail macaques distinguished between the optical isomers of five of six substances tested (Laska et al. 2005). They only failed to distinguish between the isomers of limonene oxide, while South African fur seals succeeded with this enantiomer. Honeybees (Laska \& Galizia 2001) successfully discriminated between five of eight enantiomeric odor pairs tested. In contrast, CD-1 mice and Asian elephants succeeded in discriminating between all eleven and twelve pairs of enantiomers, respectively (Laska \& Shepherd 2007, Rizvanovic 2012). Rats also successfully discriminated all three optical isomers tested (Linster et al. 2001, Rubin \& Katz 2001).

Table 2. Across-species comparison of discrimination performance with enantiomers.

\begin{tabular}{|c|c|c|c|c|c|c|c|c|}
\hline 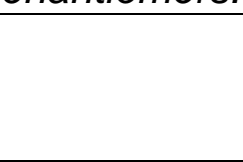 & $\begin{array}{c}\text { South } \\
\text { African } \\
\text { fur } \\
\text { seals }\end{array}$ & $\begin{array}{l}\text { CD-1 } \\
\text { mice }\end{array}$ & $\begin{array}{l}\text { Human } \\
\text { subjects }\end{array}$ & $\begin{array}{c}\text { Squirrel } \\
\text { monkeys }\end{array}$ & $\begin{array}{c}\text { Pigtail } \\
\text { macaques }\end{array}$ & $\begin{array}{c}\text { Honey } \\
\text { bees }\end{array}$ & $\begin{array}{c}\mathrm{SD} / \mathrm{LE} \\
\text { rats }\end{array}$ & $\begin{array}{l}\text { Asian } \\
\text { elephants }\end{array}$ \\
\hline carvone & + & + & + & + & + & + & + & + \\
\hline dihydrocarvone & + & + & + & + & + & & & + \\
\hline dihydrocarveol & + & + & + & + & + & & & + \\
\hline limonene & - & + & + & + & + & + & + & + \\
\hline limonene oxide & + & + & - & - & - & & & + \\
\hline isopulegol & - & + & - & - & + & & & + \\
\hline menthol & + & + & - & - & & + & & + \\
\hline beta-citronellol & + & + & - & - & & + & & + \\
\hline rose oxide & - & + & - & - & & - & & + \\
\hline fenchone & + & + & - & + & & - & + & + \\
\hline alpha-pinene & + & & + & + & & + & & + \\
\hline camphor & - & + & - & - & & - & & + \\
\hline Success & $8 / 12$ & $11 / 11$ & $5 / 12$ & $6 / 12$ & $5 / 6$ & $5 / 8$ & $3 / 3$ & $12 / 12$ \\
\hline
\end{tabular}

According to the criterion of $67.5 \%$ correct choices (corresponding to $p<0.05$ ), a ' + ' indicates that the subjects, as a group, succeeded in discriminating between the enantiomers of a given odor pair, and a '-' indicates they failed to do so. The figures in the bottom row indicate how many out of the total number of odor pairs tested were successfully discriminated by a given species. 
It is interesting to note that all species tested so far succeeded in discriminating between the enantiomers of carvone, dihydrocarvone, dihydrocarveol, and alpha-pinene. In contrast, all species except mice and elephants failed to discriminate between the enantiomers of rose oxide and camphor (see Table 2).

\subsection{Relationship between discrimination performance and molecu- lar structures}

In order to address the question why the fur seals succeeded in discriminating between the (+)- and the (-)-form of carvone, dihydrocarvone, dihydrocarveol, limonene oxide, menthol, beta-citronellol, fenchone, and alphapinene, but failed to distinguish between the enantiomers of limonene, isopulegol, rose oxide, and camphor, the structural differences and similarities among substances can be considered based on the substance selectivity theory in mammalian olfactory system (Spehr \& Munger 2009).

Previous studies on olfactory discrimination between enantiomeric odor pairs discussed the relationship between molecular structures and discrimination performance. Linster et al. (2001) pointed out the molecular structural differences between three enantiomeric odor pairs that were tested to explain the olfactory discrimination performance of rats. The presence of certain molecular structures such as an isopropenyl group, a methyl group, and an oxygen-containing functional group appeared to be common features in several discriminable enantiomeric substances tested with other species (Laska et al. 1999, Laska \& Galizia 2001, Laska 2004, Laska et al. 2005).

Similar features were found in the present study. Among the eight enantiomeric odor pairs that were discriminated by the fur seals, seven odor pairs (carvone, dihydrocarvone, dihydrocarveol, limonene oxide, menthol, betacitronellol, and fenchone) bear an oxygen-containing functional group, and five of them (carvone, dihydrocarvone, dihydrocarveol, limonene oxide, and menthol) also share an isopropenyl group at the chiral center. In contrast, three of the four enantiomeric odor pairs that were not discriminated (limonene, rose oxide, and camphor) lack either of these molecular structures (see Figure 3). Additionally, it was found that in six of the eight discriminated optical isomers a methyl group is located at the chiral center. Therefore, it seems reasonable to postulate that the combined presence of a) an oxygen-containing functional group, b) an isopropenyl group, and c) a methyl group at the chiral center might be factors that allowed the animals 
to discriminate between the optical isomers (see Table 3).

However, it should be noted that not all the results comply with this idea. The animals as a group failed to discriminate between the enantiomers of isopulegol, despite the fact that these odorants contain all structural features shared in discriminated substances. Conversely, the enantiomers of alphapinene were discriminated by all three animals tested, despite the fact that these odorants are lacking all three features. Another interesting note is that dihydrocarveol was discriminated by all four animals, though it differs from isopulegol only in the location of an alcohol group at the carbon ring (see Figure 3). These findings support the argument of Nandi (2005) that the presence of a certain chemical structure is not sufficient to predict whether or not the corresponding enantiomers are discriminable.

Table 3. Discriminability and structural features of the 12 enantiomeric odor pairs tested.

\begin{tabular}{ccccc}
\hline & Discriminability & $\begin{array}{c}\text { Isopropenyl } \\
\text { group }\end{array}$ & $\begin{array}{c}\text { Oxygen-containing } \\
\text { functional group }\end{array}$ & $\begin{array}{c}\text { Methyl group } \\
\text { at chiral center }\end{array}$ \\
\hline dihydrocarveol & + & + & + & + \\
dihydrocarvone & + & + & + & + \\
menthol & + & + & + & + \\
limonene oxide & + & + & + & + \\
carvone & + & + & + & - \\
beta-citronellol & + & - & + & + \\
fenchone & + & - & + & + \\
alpha-pinene & + & - & + & + \\
isopulegol & - & + & + & + \\
rose oxide & - & - & - & - \\
limonene & - & + & + & + \\
camphor & - & - & + & + \\
\hline
\end{tabular}

In the discriminability column, a '+' indicates that the animals discriminated at the group level, and a '-' indicates failure to discriminate. In the other columns, a '+' indicates the presence of the feature, and a '-' indicates its absence.

\subsection{Enantiomers in the chemical environment of the fur seals}

Recent studies support the hypothesis that the olfactory capacity of a species may be affected by its chemical environment (Laska \& Galizia 2001, Laska et al. 2010). When the fur seals' natural chemical environment is considered, the result of the present study is surprising, given that the enantiomeric odor pairs used in this study are mostly found in essential oils of vascular plants such as oranges and pines which are not common in the 
environment of fur seals (Bouwmeester et al. 1995, Demirci et al. 2002, Talei \& Mosavi 2009). However, only little is known about the chemical composition of the marine and terrestrial environments inhabited by fur seals. Although there is a vast amount of literature on chemical analyses of fish odors, which make up one important part of the chemical environment of fur seals (Alasalvar et al. 1997, Kowalevsky et al. 2006, Ganeko et al. 2008), the presence of enantiomers has not been reported. The enantiomers that were tested in the present study are all plant-derived, and thus unlikely to be prominent in the marine environment. Nevertheless, the possibility cannot be entirely excluded that enantiomeric odorants exist in the fur seals' chemical environment. Enantiomeric odorants might also be produced by the fur seals themselves and might serve a function in a behavioral context such as social communication so that they have developed olfactory capacity to distinguish between them. Therefore, further studies on enantiomeric substances in a broad range of chemical environment such as the marine, the terrestrial, and the body of fur seals should be conducted to corroborate the results of the present study.

\section{Conclusion}

The present study showed that the fur seals were capable of discriminating between the majority of the enantiomeric odor pairs tested. Cross-species comparisons of the fur seals' performance with that of other species previously tested on the same enantiomeric odor pairs lend further support to the notion that the relative size of olfactory brain structures does not necessarily indicate its olfactory discrimination capacity. The results suggest that the sense of smell may play an important and hitherto underestimated role in regulating the behavior of fur seals.

\section{Acknowledgement}

I would like to thank my supervisor Professor Matthias Laska, who allowed me to conduct this study and gave me a lot of advice and support all the time. I also thank all the trainers in dolphinarium in Kolmården Wild Animal Park, especially Sunna Edberg, Therese Höglin, Tova Hansson, and Christian Bauer, for the crucial help with data collection and their warmhearted attitude toward me. Finally, I thank Mats Amundin for the support during my study in Kolmården.

\section{Reference}


Alasalvar C, Quantick PC, Grigor JM (1997) Aroma compounds of fresh and stored mackerel (Scomber scombrus). pp 39-54 in: Shahidi F, Cadwallader KR (eds) Flavor and lipid chemistry of seafoods. ACS Symposium Series, 674. Washington, DC.

Amo L, Avilés JM, Parejo D, Peña A, Rodríguez J, Tomás G (2012) Sex recognition by odour and variation in the uropygial gland secretion in starlings. Journal of Animal Ecology in press.

Bang BG, Cobb S (1968) The size of the olfactory bulb in 108 species of birds. Auk 85, 55-61

http://www.jstor.org/pss/4083624 (accessed 4 March 2012)

Benvenuti S, Fiaschi V, Foa A (1977) Homing behaviour of pigeons disturbed by application of an olfactory stimulus. Journal of Comparative Physiology 120, 173-179

Bouwmeester HJ, Davies JAR, Toxopeus H (1995) Enantiomeric composition of carvone, limonene, and carveols in seeds of dill and annual and biennial caraway varieties. Journal of Agricultural and Food Chemistry 43, 3057-3064

Catania KC, Hare JF, Campbell KL (2008) Water shrews detect movement, shape, and smell to find prey underwater. Proceedings of the National Academy of Sciences of the United States of America 105, 571-576

Caspers BA, Tobias KE (2011) Odour-based natal nest recognition in the zebra finch (Taeniopygia guttata), a colony-breeding songbird. Biology Letters 7, 184-186

Demirci B, Tabanca N, Baser KHC (2002) Enantiomeric distribution of some monoterpenes in the essential oils of some Salvia species. Flavour and Fragrance Journal 17, 54-58

Fobes JL, Smock CC (1981) Sensory capacities of marine mammals. Psychological Bulletin 89, 288-307

Ganeko N, Shoda M, Hirohara I, Bhadra A, Ishida T, Matsuda H, Takamura H, Matoba T (2008) Analysis of volatile flavor compounds of sardine (Sardinops melanostica) by solid phase microextraction. Journal of Food Science 73, 83-88 
Hardy MH, Roff E, Smith TG, Ryg M (1991) Facial skin glands of ringed and grey seals, and their possible function as odoriferous organs. Canadian Journal of Zoology 69, 189-200

Kovacs KM (1995) Mother-pup reunions in harp seals, Phoca groenlandica: cues for the relocation of pups. Canadian Journal of Zoology $73,843-849$

Kowalewsky S, Dambach M, Mauck B, Dehnhardt G (2006) High olfactory sensitivity for dimethyl sulphide in harbour seals. Biology Letters 2, 106-109

Kuzin AY, Sobolevsky YI (1976) Morphological and functional characteristics of the fur seal's respiratory system. Proceeding of the $6^{\text {th }}$ All-Union Conference on the Study of Marine Mammals, Kiev, 1-3 Oct 1975:168-170. Joint Publ. Service, Arlington.

Laska M (2004) Olfactory discrimination ability of human subjects for enantiomers with an isopropenyl group at the chiral center. Chemical Senses 29, 143-152

Laska M, Freyer D (1997) Olfactory discrimination ability for aliphatic esters in squirrel monkeys and humans. Chemical Senses 22, 457-465

Laska M, Galizia CG (2001) Enantioselectivity of odor perception in honeybees. Behavioral Neuroscience 115, 632-639

Laska M, Shepherd GM (2007) Olfactory discrimination ability of CD-1 mice for a large array of enantiomers. Neuroscience 144, 295-301

Laska M, Teubner P (1999) Olfactory discrimination ability of human subjects for ten pairs of enantiomers. Chemical Senses 24, 161-170

Laska M, Liesen A, Teubner P (1999) Enantioselectivity of odor perception in squirrel monkeys and humans. American Journal of Physiology 277, R1098-R1103

http://ajpregu.physiology.org/content/277/4/R1098.full (accessed 4 March 2012)

Laska M, Genzel D, Wieser A (2005) The number of functional olfactory 
receptor genes and the relative size of olfactory brain structures are poor predictors of olfactory discrimination with enantiomers. Chemical Senses $30,171-175$

Laska M, Svelander M, Amundin M (2008) Successful acquisition of an olfactory discrimination paradigm by South African fur seals, Arctocephalus pusillus. Physiology \& Behavior 93, 1033-1038

Laska M, Lord E, Selin S, Amundin M (2010) Olfactory discrimination of aliphatic odorants in South African fur seals (Arcocephalus pusillus). Journal of Comparative Psychology 124, 187-193

Lowell WR, Flanigan Jr WF. (1980) Marine mammal chemoreception. Mammal Review 10, 53-59

Linster C, Johnson BA, Yue E, Morse A, Xu Z, Hingco EE, Choi Y, Choi M, Messiha A, Leon M (2001) Perceptual correlates of neural representations evoked by odorant enantiomers. The Journal of Neuroscience 21, 98379843

http://www.mendeley.com/research/odorant-enantiomers/ (accessed 4 March 2012)

Miller E H (1974) Social behaviour between adult male and female New Zealand fur seals, Arctocephalus forsteri (Lesson) during the breeding season. Australian Journal of Zoology 22, 155-173

Nandi N (2005) Study of chiral recognition of model peptides and odorants: carvone and camphor. Current Science 88, 1929-1937 http://www.iisc.ernet.in/currsci/jun252005/1929.pdf (accessed 4 March 2012)

Pitcher BJ, Harcourt RG, Schaal B, Charrier I (2011) Social olfaction in marine mammals: wild female Australian sea lions can identify their pup's scent. Biology Letters 7, 60-62

Reep RL, Finlay BR, Darlington RB (2007) The limbic system in mammalian brain evolution. Brain, Behavior and Evolution 70, 57-70

Rizvanovic A (in prep.) Olfactory discrimination performance and longterm odor memory in Asian elephants (Elephas maximus). M.Sc. thesis, Linköping University. 
Ross GJB (1972) Nuzzling behaviour in captive Cape fur seals. International Zoo Yearbook 12, 183-184

Rubin BD, Katz LC (2001) Spatial coding of enantiomers in the rat olfactory bulb. Nature Neuroscience 4, 355-356

Ryg M, Solberg Y, Lydersen C, Smith TG (1992) The scent of rutting male ringed seals (Phoca hispida). Journal of Zoology 226, 681-689

Talei GR, Mosavi Z (2009) Chemical composition and antibacterial activity of Bunium persicum from west of Iran. Asian Journal of Chemistry 21, 4749-4754 http://www.cabdirect.org/abstracts/20093257662.html (accessed 4 March 2012)

Trimble M, Insley SJ (2010) Mother-offspring reunion in the South American sea lion Otaria flavescens at Isla de Lobos (Uruguay): use of spatial, acoustic and olfactory cues. Ethology Ecology \& Evolution 22, 233-246

Spehr M, Munger SD (2009) Olfactory receptors: G protein-coupled receptors and beyond. Journal of Neurochemistry 109, 1570-1583

Watkins WA, Wartzock D (1985) Sensory biophysics of marine mammals. Marine Mammal Science 1, 219-260

Welty JC (1975) The life of birds. 2nd ed. W. B. Saunders Company, Philadelphia 